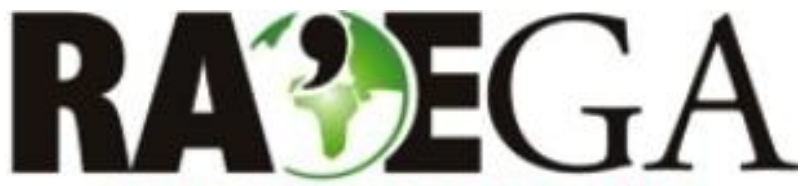

O ESPACO GEOGRÁFICO EM ANÁLISE

\title{
A GEOGRAFIA DO MERCADO MUNDIAL DE PRODUTOS AGROALIMENTARES E O PAPEL DO BRASIL
}

\section{THE GEOGRAPHY OF WORLD MARKET FOR AGRICULTURAL PRODUCTS AND THE ROLE OF BRASIL}

\author{
Marlon Clovis Medeiros \\ Professor da Universidade Estadual do Oeste do Paraná (UNIOESTE) \\ Centro de Ciências Humanas \\ Francisco Beltrão, PR \\ e-mail:mcmedeiros@yahoo.com.br
}

\section{Recebido em: 01/08/2013}

Aceito em: 28/02/2014

\section{Resumo}

$\mathrm{O}$ artigo analisa as mudanças recentes na geografia do mercado mundial de produtos agrícolas, discutindo a inserção do Brasil, o papel dos mercados futuros na elevação dos preços internacionais e as mudanças entre os países exportadores e importadores de produtos agrícolas. Argumentamos que a principal mudança no espaço agrícola mundial nas últimas duas décadas foi 0 crescimento dos investimentos financeiros em commodities agrícolas e o crescimento dos mercados de futuros. A dinâmica financeira se tornou dominante nos mercados agrícolas, levando à mudanças nas safras e nos preços, tornando-os subordinados à expectativa de retorno dos investidores. Este foi o principal elemento da inflação de preços agrícolas em 2006-2008. Estudos dos mais diversos organismos internacionais (FAO, FMl e Banco Mundial) apontaram cenários de agravamento da fome em inúmeros países e de continuidade da alta de preços, mas desviaram o foco do papel da especulação, apontando duas grandes causas: a produção de biocombustíveis e o aumento do consumo de alimentos na Ásia. No presente artigo argumentamos pelo contrário, que o papel das vendas antecipadas nas bolsas de mercadorias e futuros, foi o elemento determinante. A oferta e a demanda agrícola vem perderam espaço como reguladores de preços para a antecipação e expectativas dos mercados futuros. Os preços são determinados antes mesmo do plantio. A ampliação dos fluxos internacionais de capital e as crises financeiras trouxeram a dinâmica internacional para o centro dos debates geográficos e sobre os rumos da agricultura. 
Palavras-chave: Geografia Econômica, Agricultura Brasileira, Commodities Agrícolas, Mercados Futuros, Comércio Mundial.

\begin{abstract}
This article analyzes the recent changes in the geography of the world market agricultural products, discussing Brazilian integration, the role of futures markets in the increase in international prices and the changes between the exporting and importing of agricultural products countries. It is argued that the main change in world agricultural space over the past two decades has been the growth of investments in agricultural commodities and growth of the futures markets. The financial dynamics became dominant in agricultural markets, leading to changes in yields and prices, making them subject to the expected return of investors. This was the main element of inflation in agricultural prices in 2006-2008. Studies from various international organizations (FAO, World Bank and IMF) pointed scenarios of worsening hunger in many countries and continued high prices, but diverted the focus of the role of speculation, pointing two major causes: the production of biofuels and increased consumption of food in Asia. In this paper we argue the contrary, that the role of anticipated sales in commodities and futures, was the decisive factor. The agricultural supply and demand has lost ground as regulators of prices for the anticipation and expectations of future markets. Prices are determined before planting. The expansion of international capital flows and financial crises have brought the international dynamics towards the center of the geographical analysis and about the future of agriculture.
\end{abstract}

Keywords: Economic Geography, Brazilian Agriculture, Agricultural Commodities, Future Markets, World Trade.

\title{
INTRODUÇÃO
}

A geografia econômica periodicamente desenvolve novas áreas de estudos de acordo com as questões postas nas diferentes conjunturas. Há décadas Monbeig (1957) alertava para a necessidade de uma geografia do capital, que investigasse o papel do capital financeiro nas atividades produtivas. As mudanças mundiais desde a década de 1990, com grande ampliação dos fluxos internacionais de capital, formação de sucessivas bolhas e crises financeiras trouxeram a dinâmica internacional para o centro dos debates geográficos e sobre os rumos da agricultura em particular. As mudanças espaciais ocasionadas pela dinâmica financeira na agricultura mundial são fundamentais para a análise geográfica.

Para além dos estudos sobre dinâmicas regionais reascendeu-se o debate sobre o mercado mundial de produtos agrícolas e sobre os investimentos financeiros nestes. O grande volume de negócios com commodities agrícolas nos mercados 


\section{A geografia do mercado mundial de produtos agroalimentares e o papel do Brasil}

futuros de todo o mundo, junto à alta dos preços destas, nos anos de 2006 a 2008 reanimou os debates sobre a dinâmica dos mercados mundiais de produtos agroalimentares, sobre os fatores determinantes das mudanças de preços e sobre a influência do capital financeiro.

Estudos dos mais diversos organismos internacionais, especialmente da FAO, do FMI e do Banco Mundial apontaram cenários de agravamento da fome em inúmeros países e de continuidade da alta de preços. No entanto, estes estudos desviaram o foco do papel da especulação no aumento de preços, apontando, quase unanimemente, duas grandes causas: relatórios como FAO (2008), FMI (2008), embora divergentes em determinados aspectos, apontaram a produção de biocombustíveis (especialmente do etanol de milho) e o aumento do consumo de alimentos, especialmente nos países asiáticos. No presente artigo, buscamos argumentar pelo contrário, que o papel das vendas antecipadas nas bolsas de mercadorias e futuros, foi o elemento determinante, uma vez que os demais fatores passam a ser determinados por este.

Os fatores tradicionais da oferta e demanda agrícola, vem perdendo espaço como reguladores de preços, há décadas, para a antecipação e expectativas dos mercados futuros e seus investidores. Os preços são determinados antes mesmo do plantio das colheitas.

A dinâmica do mercado mundial de produtos agrícolas e das bolsas de mercadorias e futuros é fundamental para a compreensão da agricultura brasileira. A oscilação de períodos de importação e exportação e a internalização da demanda e dos preços internacionais influenciou toda a agricultura nacional, e não apenas aquela ligada às exportações. No Brasil, os mercados externos cresceram em importância a partir da década de 1990, pela ampliação das importações que acirraram a concorrência no mercado interno, levando à crise, reestruturação e concentração da produção; pelas fusões e aquisições de empresas brasileiras por grupos estrangeiros nos setores de alimentos e agroquímicos; pela ampliação das exportações brasileiras de produtos agrícolas; pela ampliação dos financiamentos de lavouras no Brasil pelas tradings internacionais. 
Assim, o objetivo central do artigo é discutir o papel crescente dos fluxos de capital aplicados nas commodities agrícolas, especialmente via bolsas de futuros, e seu papel no crescimento dos preços agrícolas no período 2007-2008.

O presente artigo se insere numa geografia econômica que põe a análise da acumulação de capital e o desenvolvimento dos setores econômicos em primeiro plano. Como afirmou Monbeig (1957), o capital é um dos agentes geográficos mais eficientes, sendo o estudo dos investimentos tão central quanto o estudo das técnicas de produção e das condições naturais, na análise das atividades agrícolas.

$\mathrm{O}$ artigo encontra-se dividido em três partes. Na primeira analisamos as mudanças recentes na geografia do mercado mundial de produtos agroalimentares, na segunda discutimos o papel das bolsas de mercadorias e futuros na alta dos preços. Na terceira parte analisamos a inserção do Brasil ressaltando as mudanças nos mecanismos de financiamento da produção e a influência dos grandes grupos agroindustriais estrangeiros.

\section{O MERCADO MUNDIAL DE PRODUTOS AGROALIMENTARES}

Uma das características fundamentais do mercado mundial na última década foi a ampliação do volume de capital aplicado em commodities. Com a crise asiática em 1998 e a quebra dos investimentos em empresas de internet em 2000 (o estouro da "bolha.com"), vultosos recursos financeiros procuraram aplicações mais seguras. Além das crises, relatórios do $\mathrm{FMI}^{1}$ sobre a economia mundial demonstram que o período de 2002 a 2007 foi de queda das taxas de juros mundiais, levando a diminuição da lucratividade de ativos financeiros, em especial os títulos de dívidas dos Estados. Acompanhando essa queda, grande volume de recursos migrou para os mercados de commodities.

As commodities agrícolas, minerais e energéticas passaram a ocupar papel de destaque nos mercados financeiros, impulsionando as bolsas de mercadorias e futuros. Ao lado disto, ocorreu expressiva ampliação do comércio mundial destas mesmas commodities. Em toda a década de 1990 o comércio mundial ampliou-se em 65\%, enquanto apenas no período 2000-2010, aumentou em 136,5\%. As

\footnotetext{
${ }^{1}$ International Monetary Found, World Economic Outlook 2008. Disponível em www.imf.org.
} 


\section{A geografia do mercado mundial de produtos agroalimentares e o papel do Brasil}

exportações totais de produtos agrícolas crescem 31,2\% entre 1990-99 e 147,4\% no período 2000-2010 (sendo 92\% apenas no período 2002-2007, quando os preços iniciam alta no mercado internacional).

Assim, na década de 2000 o crescimento do mercado de produtos agrícolas é maior que o crescimento total do comércio mundial, passando de $8,4 \%$ do total para 9,4\% em $2009^{2}$. É um crescimento expressivo, uma vez que desde 1983 os produtos agrícolas decresciam como parcela do comércio mundial total ${ }^{3}$. Isto se relaciona ao fato de os países desenvolvidos, que detém maior participação no comércio mundial, priorizarem as exportações de produtos industrializados e serviços e importarem matérias-primas e produtos agrícolas. As exportações agrícolas cresceram como proporção das exportações totais em países periféricos, como Brasil, Argentina e Chile.

$\mathrm{Na}$ tabela número 1 observa-se o crescimento do mercado mundial de produtos agrícolas. $O$ crescimento dos preços agropecuários e da demanda por alimentos possibilitaram grande aumento do comércio internacional de produtos agrícolas.

Todas as regiões tradicionalmente produtoras agrícolas ampliaram seus volumes comercializados, mas com aumento significativo da participação dos países da América Latina e da Ásia. Os Estados Unidos perderam em participação nas exportações totais, mas continuam ampliando seus volumes exportados e detém ainda $10 \%$ do mercado mundial de produtos agrícolas. A União Europeia mantém sua participação em torno de $40 \%$ do mercado mundial. Tanto Europa quanto os EUA aumentaram sua importações agrícolas significativamente, o que explica a persistência do protecionismo e das políticas de incentivo.

\footnotetext{
${ }^{2}$ Dados da OMC, disponíveis em www.wto.org, International Statistics Database.

${ }^{3}$ Os produtos agrícolas entraram em 1994 na pauta do GATT O Acordo Geral de Tarifas e Comércio-GATT na sigla em inglês é o mecanismo precursor da OMC nas questões relacionadas ao comércio mundial.
} 
A geografia do mercado mundial de produtos agroalimentares e o papel do Brasil

Tabela 1 - Exportações agrícolas por países selecionados

\begin{tabular}{c|r|r|r|r|r|r|r|r}
\hline & \multicolumn{3}{|c|}{ US\$ Milhões } & \multicolumn{2}{c|}{ Cresc. Acum. } & \multicolumn{2}{c}{ Partic. \% no total } \\
\hline & \multicolumn{1}{|c|}{$\mathbf{1 9 9 0}$} & $\mathbf{2 0 0 0}$ & $\mathbf{2 0 1 0}$ & $\begin{array}{c}\mathbf{1 9 9 0 -} \\
\mathbf{2 0 0 0}\end{array}$ & $\begin{array}{r}\mathbf{2 0 0 0}- \\
\mathbf{2 0 1 0}\end{array}$ & $\mathbf{1 9 9 0}$ & $\mathbf{2 0 0 0}$ & $\mathbf{2 0 1 0}$ \\
\hline Mundo & 414.723 & 552.345 & 1.366 .469 & 33,2 & 247,4 & 100 & 100 & 100 \\
\hline Argentina & 7.482 & 11.954 & 34.643 & 59,8 & 289,8 & 1,8 & 2,2 & 2,5 \\
\hline Austrália & 11.875 & 16.446 & 27.048 & 38,5 & 164,5 & 2,9 & 3 & 2,0 \\
\hline Brasil & 9.779 & 15.467 & 68.585 & 58,2 & 443,4 & 2,4 & 2,8 & 5,0 \\
\hline Canadá & 22.339 & 34.789 & 52.128 & 55,7 & 149,8 & 5,4 & 6,3 & 3,8 \\
\hline Chile & 2.779 & 6.399 & 15.746 & 130,2 & 246,1 & 0,7 & 1,2 & 1,2 \\
\hline China & 10.060 & 16.384 & 51.607 & 62,9 & 315,0 & 2,4 & 3 & 3,8 \\
\hline França & 37.101 & 36.939 & 68.506 & $-0,4$ & 185,5 & 8,9 & 6,7 & 5,0 \\
\hline Alemanha & 24.621 & 29.275 & 80.275 & 18,9 & 274,2 & 5,9 & 5,3 & 5,9 \\
\hline Itália & 11.858 & 16.357 & 38.627 & 37,9 & 236,1 & 2,9 & 3 & 2,8 \\
\hline Holanda & 31.859 & 42.010 & 94.051 & 31,9 & 223,9 & 7,7 & 7,6 & 6,9 \\
\hline Espanha & 9.368 & 17.466 & 42.089 & 86,4 & 241,0 & 2,3 & 3,2 & 3,1 \\
\hline Reino Unido & 14.961 & 17.069 & 28.999 & 14,1 & 169,9 & 3,6 & 3,1 & 2,1 \\
\hline $\begin{array}{c}\text { Estados } \\
\text { Unidos }\end{array}$ & 59.404 & 71.408 & 142.538 & 20,2 & 199,6 & 14,3 & 12,9 & 10,4 \\
\hline $\begin{array}{c}\text { União } \\
\text { Européia (27 } \\
\text { países) }\end{array}$ & - & 229.313 & 534.892 & $\mathrm{n} / \mathrm{d}$ & 233,3 & & 41,5 & 39,1 \\
\hline
\end{tabular}

Fonte: OMC

O Brasil foi um dos países que ampliou mais significativamente a participação no comércio mundial de produtos agrícolas, de 2,8\% em 2000 para 5,0\% em 2010. Durante a década de 1990, esta participação havia se estabilizado em pouco mais de $2 \%$. Enquanto o total das exportações agrícolas mundiais cresceu 247,4\% no período 2000-2010, as exportações agrícolas brasileiras cresceram 443,4\%. A Rússia também apresentou expressivo crescimento das exportações de $203 \%$ de 2000 a 2007. No mesmo período, os Estados Unidos ampliaram as exportações agrícolas em 59\%, a União Européia em 112\%, a China em 137\%, a Argentina em $140 \%$, o Chile em $113 \%$, a França em $77 \%$ e o Canadá em $40 \%$. Os dados demonstram que o crescimento mais intenso das exportações agrícolas ocorreu nos países periféricos. Isto se relaciona diretamente ao aumento dos investimentos financeiros nos produtos agropecuários após as inúmeras crises financeiras da década de 1990.

Os países da Ásia, além do crescimento das exportações, ampliaram significativamente as importações. O crescimento econômico da região possibilitou melhoria das condições de alimentação de milhões de pessoas, levando ao aumento 
das importações ${ }^{4}$. É importante ressaltar que não se trata apenas de aumento no consumo de alimentos, mas de uma mudança qualitativa. A China, por exemplo, vem passando por mudança nos hábitos da população, semelhante ao que ocorreu no Japão nas décadas de 1960/70, com aumento do consumo de proteínas animais e de óleos vegetais e estabilização do consumo de produtos tradicionais como o arroz. Esta mudança é semelhante a que ocorreu no início do século XX nos países da Europa ocidental, como discutiu Guglielmo (1975) e em período mais recente no Brasil, como discutido em estudos de geógrafos como Carvalho (2001) e Medeiros (2009 e 2010).

China, Índia, Cingapura, Vietnã, Tailândia e Malásia, que importaram em 2000 US\$ 38,7 bilhões, chegaram em 2007 ao valor de US\$ 108,2 bilhões de importações agrícolas. Adicionando a este valor as importações de países asiáticos que já importavam grandes volumes anteriormente, como Japão, Coréia do Sul, Hong Kong e Taiwan chega-se ao valor de US\$223,3 bilhões em 2007. Este valor apresentou um aumento de $67,3 \%$ sobre o ano 2000 para o conjunto dos países asiáticos citados, mas um aumento bem mais expressivo se tomarmos alguns casos em separado: $233,8 \%$ para a China; $142,2 \%$ para a Índia, mas apenas $10,7 \%$ para o Japão.

O aumento do consumo e das importações agrícolas não ocorreu somente na Ásia, mas as expectativas concentravam-se em especial nestes países, com destaque para a China que passa de $1,9 \%$ das importações mundiais em 1990, para $3,5 \%$ em 2000 e $5,8 \%$ em 2007. O aumento total das exportações agrícolas mundiais foi da ordem de $33,2 \%$ de 1990 a 2000 , acelerando-se a $104,2 \%$ de 2000 a 2007.

Mesmo com pequena participação nas exportações, o setor agrícola nos Estados Unidos e na Europa obtém farto protecionismo e subsídios às exportações.

\footnotetext{
${ }^{4}$ Conforme estudo da FAO (2006) demonstra, o número de pessoas subnutridas na região da Ásia e Pacífico caiu de 569,7 milhões em 1990-92 para 524 milhões em 2001-2003. Apenas na Coréia do Norte este número se elevou de 18 milhões para 35 milhões de pessoas no mesmo período, devido aos problemas de escassez de alimentos que esta passou a enfrentar após o fim da URSS, e com o bloqueio econômico norte-americano. Na China, o número de pessoas que saiu da linha da subnutrição alcançou a cifra de 43,6 milhões. No Vietnã, embora bem mais modesto em números absolutos, a população subnutrida passou de $31 \%$ do total, para $17 \%$. $\mathrm{Na}$ América Latina e Caribe, por outro lado, a população subnutrida reduziu-se em apenas sete milhões, ao passo que se ampliou no Oriente Médio e Norte da África em 12,6 milhões e na África Sub-Sahariana em 37,2 milhões.
} 


\section{A geografia do mercado mundial de produtos agroalimentares e o papel do Brasil}

Estes mantém o setor agrícola como estratégico à política nacional, mesmo que economicamente seu papel venha se reduzindo gradativamente. Enquanto o Brasil, na virada da década de 1980 para 90, reduzia o apoio à agricultura e abria o mercado para as importações, a União Européia e os Estados Unidos mantinham as proteções e subsídios aos produtores impondo cotas e taxas aos produtos importados. Mesmo com as novas normas da OMC contra subsídios, a situação se manteve, pois como Estados Unidos, Canadá e outros países desenvolvidos elaboraram as normas da OMC, adaptaram estas aos incentivos por eles praticados (HOLANDA FILHO, 2005).

$\mathrm{Na}$ rodada de Doha, hora em realização, permanece o mesmo impasse quanto ao protecionismo agrícola dos países centrais. No governo Bush houve ampliação dos subsídios inseridos na "Farm Bill", a política oficial norte-americana de ajuda à agricultura. Os lobbies do setor de carnes, açúcar e suco de laranja são tradicionais e poderosos na política norte-americana, conseguindo viabilizar políticas de proteção contra importações e incentivos às exportações. A política de incentivos favorece a expansão internacional das grandes tradings norte-americanas como Cargill e $\mathrm{ADM}^{5}$.

As tarifas de importação têm dois objetivos na União Européia. Por um lado visam proteger o produtor interno da concorrência internacional e por outro, visam dificultar que os países exportadores (não apenas os periféricos, mas também os EUA) ampliem suas vendas de produtos mais elaborados. Assim, há importação de matérias-primas para que a industrialização seja feita internamente. Como aponta Prates (2007, p. 327 e 328):

Essas políticas- que afetam principalmente, as categorias de commodities
primárias e manufaturas de baixa intensidade tecnológica- ancoravam-se (e
ainda se ancoram) em dois pilares: tarifas escalonadas, crescentes com o
grau de processamento dos bens, que desestimulam o processamento das
commodities pelos países periféricos; e subsídios agrícolas que, ao
estimularem a manutenção ou aumento da produção, deprimem os preços
mundiais dos produtos. No caso da União Européia, esses subsídios

\footnotetext{
${ }^{5}$ Logo após a II Guerra Mundial o governo dos EUA aprovou a Lei 480, a primeira com objetivo explícito de incentivar as exportações agrícolas e a expansão internacional dos grandes grupos empresariais da área alimentar, como apontaram Burbach e Flynn (1982). Esta lei vigorou por décadas e abriu o mercado mundial, em especial dos países subdesenvolvidos às empresas norte-americanas. Deste período em diante sempre vigoraram os subsídios e incentivos como elemento estrutural da agricultura e da agroindústria norte-americana.
} 
restringiram o acesso ao mercado exatamente para os produtos com maior elasticidade-renda da demanda. Também vale lembrar que a Rodada do Uruguai de 1994, além de ter determinado a redução das tarifas principalmente para os produtos industriais (com exceção dos setores têxtil e de vestuário) vis-à-vis aos agrícolas, introduziu as Tariff Rate Quotas (TRQs) - tarifas diferenciadas de acordo com a quantidade importada -, que se concentram exatamente nessas commodities com maior elasticidade-renda da demanda (como frutas e vegetais, carne, cereais, laticínios e sementes oleaginosas).

Desde a década de 1990, na rodada do Uruguai, o protecionismo agrícola gerou inúmeras discussões entre os países periféricos como o Brasil e a Índia interessados em ampliar as exportações agrícolas. Como apontou Holanda Filho (2005, p. 19):

\begin{abstract}
Numa dessas sessões especiais de negociação agrícola, a união européia admitiu concessões mais imediatas de cortes nos subsídios em troca de cortes proporcionais, nos países exportadores, de medidas que estariam afetando o comércio agrícola, como a ajuda alimentar. Nesta reunião foi citada uma pesquisa da OCDE que indica que o apoio dos governos europeus à produção agrícola se mantém nos níveis que existiam antes da Rodada Uruguai. Ataques também se direcionam à política norte-americana para o setor, acusada de abuso no uso crescente de subsídios não acionáveis pela regra geral do Acordo sobre Subsídios, que teria aumentado em 700\% desde 1996.
\end{abstract}

Com o acirramento da pressão sobre os produtores da Europa e dos Estados Unidos, com o aumento da produção e exportação agrícola dos países periféricos, o protecionismo tornou-se elemento central do conflito econômico internacional. $\mathrm{O}$ grande déficit comercial dos países desenvolvidos vem agravando $\mathrm{o}$ quadro de lutas. A OMC se tornou a grande arena da geopolítica dos alimentos, como foro de resolução de controvérsias sobre questões comerciais. Países afetados por problemas de fome reivindicam "comércio mais justo" e controle de preços sobre alimentos básicos, controles sobre a especulação em commodities e redução da produção de biocombustíveis.

\title{
AS BOLSAS DE MERCADORIAS E FUTUROS E A ESPECULAÇÃO SOBRE AS COMMODITIES AGROPECUÁRIAS
}

Junto à ampliação do comércio de mercadorias, tem-se o aumento dos fluxos internacionais de capital e dos investimentos em mercados futuros de commodities. O grande aumento do consumo de alimentos, em especial nos países 


\section{A geografia do mercado mundial de produtos agroalimentares e o papel do Brasil}

asiáticos, coberto via importações, estimulou os movimentos especulativos em torno das commodities agrícolas. Assim, as expectativas em torno do aumento do consumo de produtos agrícolas, num momento de ciclo ascendente de preços, aceleraram ainda mais a elevação dos preços no mercado mundial. No ano de 2007 o movimento de bolsas de mercadorias e futuros no mundo superou em muito as safras mundiais (em equivalente-mercadoria dos contratos). Esta situação foi um dos principais responsáveis pela inflação mundial de alimentos que se estendeu até aproximadamente julho de 2008. Conforme dados de Wedekin (2008), o volume financeiro de contratos de futuros agropecuários representou números muito superiores às safras reais, em 17,2 vezes para a soja, 16, vezes para o café, 6,1 vezes para o milho e seis vezes para o açúcar.

O gráfico número 1 apresenta uma série de preços mensais de quatro commodities agrícolas: arroz, soja, trigo e milho, de 1990 a 2007. Primeiramente, chama a atenção que coincidem os períodos de oscilação dos preços das commodities agrícolas para mais ou para menos, não obstante as diferenças de patamar de preços entre elas. Da metade da década de 1990 até 2002 os preços oscilam numa trajetória de queda. A partir de 2002 os preços retornam a trajetória ascendente até 2004, junto com o crescimento do número de contratos futuros das bolsas de mercadorias, como se observa nas tabelas número 1 e 2. A partir de 2004 os preços caem, mas permanecem acima do patamar do período 2002-2004. Em 2006 os preços e o número de contratos têm grande aceleração, superando os preços máximos anteriores em junho de 2007. 


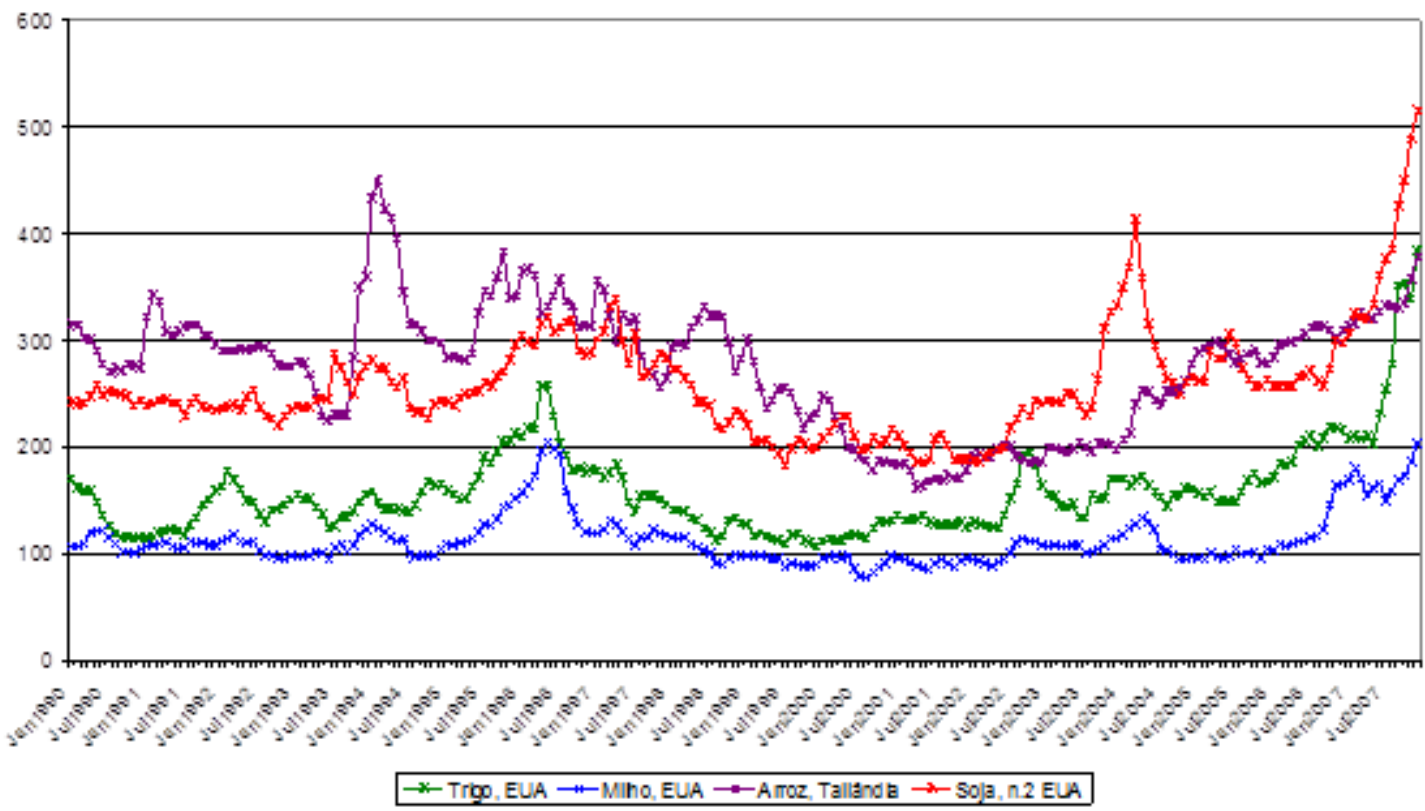

Gráfico 1: Preços Internacionais Mensais de Commodities Selecionadas (US\$/ton).

Fonte: UNCTAD. Handbook of Statistics.

Observando os preços num horizonte mais longo, desde 1990 observa-se um movimento cíclico de ascensão e queda dos preços. Ocorrem aproximadamente dois anos em trajetória ascendente e dois anos em trajetória de queda (com pequenas oscilações entre os períodos). Estas oscilações se relacionaram tradicionalmente as oscilações da oferta e demanda agrícola, por isso leva-se um tempo tão longo para a oferta aumentar em função da elevação dos preços. Até as safras atingirem o ponto de causar novo período de queda, passam-se aproximadamente dois anos. No período recente de alta dos preços, entra a influência de um elemento que não é novo, mas que cresceu de maneira acelerada de 2002 em diante: o mercado de futuros agropecuários.

Com o aumento da importância dos mercados futuros, a expectativa passa a jogar um papel central na formação dos preços. Não mais apenas as condições atuais de oferta e demanda, mas o que se espera delas para os próximos meses e o próximo ano. Passa a vigorar uma lógica de investimento financeiro no mercado de commodities, uma lógica de aposta e especulação. Com isto, o papel das corretoras de títulos e dos analistas de mercado cresce em importância levando a que o capital dos investidores se adiante as tendências próprias da agricultura, acelerando os períodos de queda ou elevação dos preços. 


\section{A geografia do mercado mundial de produtos agroalimentares e o papel do Brasil}

Criou-se uma dinâmica mais propriamente financeira no setor agroalimentar, pois as grandes bolsas, como a de Chicago (CBOT) influenciam a formação de preços no mundo inteiro. Com a facilidade de circulação e obtenção de informações, as expectativas, oscilações de preços e de da demanda nas principais bolsas e centros de decisão se difundem rapidamente e influenciam as mais distantes regiões e as negociações cotidianas de compra e venda (inclusive aquelas que não passam pelas bolsas). No Brasil, por exemplo, tornou-se comum que compradores e vendedores de grãos de todo as regiões, sempre consultem o preço do dia e o preço futuro na BM\&F antes de efetuarem suas negociações. A BM\&F e os investidores por sua vez, consultam preços internacionais, tomando por base a bolsa de Chicago. Assim, ocorre uma integração dos preços dos mercados de futuros, e para além destes, de qualquer negociação de compra e venda de produtos agrícolas com preço estabelecido nas bolsas, mesmo que não tenham relação direta com esta.

Formou-se um movimento que os economistas chamariam de uma "profecia auto-realizada", pois a expectativa de que os preços se elevariam levou ao aumento do número de contratos futuros, o que por sua vez elevou os preços. Havia uma expectativa de que as safras em 2008 e 2009 seriam inferiores a demanda mundial, justificando a elevação dos preços. Já no fim do primeiro semestre de 2008, as primeiras notícias de boas colheitas em vários locais do mundo levaram à reversão destas expectativas e início de baixa nos preços já no segundo semestre de 2008.

A tabela número 2 demonstra a variação do total mundial dos contratos futuros de 1999 a 2008. Observa-se grande aceleração do número de contratos agropecuários de 2006 a 2008, mesmo período da aceleração dos preços. Dentre as commodities, as agropecuárias apresentam o maior volume de contratos de 2003 em diante. Mesmo antes da aceleração dos preços das commodities, já havia crescimento contínuo no número de contratos desde 2002. Assim, o movimento de crescimento dos contratos futuros agropecuários (influenciado pela expectativa de contínuo crescimento dos preços) puxou para cima os preços das commodities.

A elevação do número de contratos de commodities agropecuários precede a elevação dos preços agropecuários no mercado internacional. Concomitantemente ao crescimento dos contratos com commodities, observa-se a desaceleração do 
crescimento de contratos de índices de ações, de ações individuais e de taxas de juros.

Tabela 2 - Variação Anual do Número de Contratos Futuros- Total Mundial (\%)

\begin{tabular}{l|r|r|r|r|r|r|r|r|r|r}
\hline & $\mathbf{1 9 9 9}$ & $\mathbf{2 0 0 0}$ & $\mathbf{2 0 0 1}$ & $\mathbf{2 0 0 2}$ & $\mathbf{2 0 0 3}$ & $\mathbf{2 0 0 4}$ & $\mathbf{2 0 0 5}$ & $\mathbf{2 0 0 6}$ & $\mathbf{2 0 0 7}$ & $\mathbf{2 0 0 8}$ \\
\hline Índice de Ações & 39,7 & 29,4 & 117,9 & 86,2 & 41,9 & 4,6 & 7,9 & 9,1 & 26,1 & 18 \\
\hline Ações Individuais & 32,9 & 45,3 & 14,7 & 7,2 & 15 & 28,3 & 18 & 25,8 & 42,2 & 25,2 \\
\hline Taxas de Juros & $-10,9$ & 6,6 & 44 & 13 & 27,2 & 20,7 & 11,6 & 22 & 17,4 & $-14,4$ \\
\hline Agropecuários & $-0,3$ & 35,0 & $-15,7$ & 5,4 & 30,9 & 5,5 & 9,5 & 43,5 & 32,02 & 38,7 \\
\hline Energia & 16,8 & 38,7 & 7,8 & 25,4 & 3,9 & 11,9 & 12,8 & 28,3 & 28,6 & 16,8 \\
\hline Moedas & $-38,3$ & 14,6 & 4,7 & 9,2 & 28,5 & 35,3 & 57 & 37,7 & 39,4 & 25,5 \\
\hline Metais & & & & & & & $-7,5$ & 27,8 & & \\
\hline Metais Preciosos & 8,7 & $-33,3$ & 8,2 & 30,9 & 25,7 & -6 & & & 2,7 & 19,5 \\
\hline Metais Não- & 17,1 & 7,1 & $-7,3$ & 7,7 & 26,9 & 16,4 & & & 29,7 & 64,5 \\
Preciosos & 11 & $-7,1$ & $-38,5$ & 5,7 & $-17,1$ & 0,4 & 93,5 & 66,6 & $-3,06$ & 74,1 \\
\hline Outros & 10,1 & 24,7 & 43,2 & 36,7 & 30,4 & 8,9 & 6,83 & 18,9 & 28,03 & 13,7 \\
\hline Total & & & & & & & &
\end{tabular}

Fonte: FIA, Volume Trends Webinar. Disponível em www.futureindustry.org

Ao lado do movimento recorde das bolsas de mercadorias, encontra-se em andamento mega-fusões das bolsas de mercadorias. Este movimento encontra-se mais avançado na Europa e dos Estados Unidos, mas já chega à Ásia e América Latina. Isto amplia a integração das operações das bolsas, e consequentemente a influência exercida sobre estas nos preços internacionais de commodities agrícolas. No final de 2007 fundiram-se as duas maiores bolsas de mercadorias dos Estados Unidos, a Chicago Board of Trade (CBOT) e a Chicago Mercantil Exchange (CME), originando o CME Group. Em 2008 o CME group compra a Nova York Mercantile Exchange (NYMEX), a maior bolsa mundial em termos de commodities energéticas, em especial o petróleo. Os processos de fusões entre as bolsas estão no início, e vários se encontram em negociações, em especial entre as europeias e norteamericanas.

No mesmo período, no Brasil ocorre a fusão da BM\&F com a Bovespa. No início de 2008, a BM\&F-Bovespa realiza uma associação com integração operacional com a mega bolsa CME Group. Esta associação amplia as possibilidades de movimentos de investidores e produtores nas bolsas, uma vez que agora as corretoras brasileiras podem vender seus títulos diretamente na plataforma Globex, da CBOT-CME, e vice-versa. Uma corretora brasileira de títulos agora pode 
vender diretamente na bolsa de Chicago sem a intermediação de uma corretora norte-americana. Grandes produtores agrícolas brasileiros como o Grupo Bom Futuro de Mato Grosso já estão realizando vendas diretamente na bolsa de Chicago.

As fusões de bolsas de mercadorias e futuros e bolsas de valores representam um passo adiante no processo de centralização do capital, que havia se acelerado na década de 1990, nos setores de processamento de alimentos, de biotecnologia, de produção de insumos agrícolas e de comercialização agrícola. $\mathrm{Na}$ década de 1990, a imensa centralização de capital no setor financeiro e nos fundos de investimentos dos países centrais pressiona pela abertura contínua de novas oportunidades de investimento e pela abertura dos mercados dos países periféricos. É mais uma face do velho imperialismo desvendado por Lênin no início do século XX, uma continuidade de uma tendência secular, e não um movimento novo (no sentido de mudança histórica). Os países mais desenvolvidos, tendo já esgotado suas fontes de novos lucros, partem em busca de novas formas de exportação de capital $^{6}$.

A expansão dos mercados mundiais de produtos agrícolas, alicerçados em grandes grupos monopolistas, no capital financeiro e nas bolsas de mercadorias demonstra que a ideia de modernização da agricultura dos clássicos do marxismo, especialmente Kautsky e Lenin, é um movimento profundo e concreto. Na geografia em particular há autores que apresentam uma visão caricatural do marxismo como Diniz Filho (2011), o qual acredita que a análise marxista se resume a questão da "desintegração camponesa".

\section{O PAPEL DAS GRANDES TRADINGS AGRíCOLAS E O MERCADO DE FUTUROS AGROPECUÁRIOS NO BRASIL}

A crise financeira brasileira na década de 1990, junto com a política de cortes de recursos para a agricultura levou a inúmeras situações:

a) escassez de recursos para financiamento agropecuário e aumento das taxas de juros;

\footnotetext{
${ }^{6}$ Para Lênin (1982), uma das principais características do capitalismo monopolista - o imperialismo - é que a exportação de capital torna-se mais importante que a exportação de mercadorias para os países centrais.
} 


\section{A geografia do mercado mundial de produtos agroalimentares e o papel do Brasil}

b) agravamento das crises dos produtores com dívidas mais antigas, levando a sucessivas renegociações;

c) crise generalizada da agricultura, especialmente dos pequenos e médios produtores, com poucas alternativas de financiamento;

d) busca de novas fontes de financiamento, especialmente pelos grandes produtores ligados ao setor agroindustrial ou aos mercados externos.

Nesta conjuntura ampliou-se a atuação de grandes grupos estrangeiros no agro nacional, especialmente via aquisições de empresas brasileiras, como demonstraram Benneti (2004), Aoun (2008) entre outros. A abertura ampliou a importância da BM\&F e dos mecanismos de financiamento via grupos privados, especialmente as grandes tradings internacionais. A possibilidade de captação de recursos no mercado financeiro facilitou suas operações. Com isso, os preços internacionais passaram a ser elemento central na demanda, na realização dos investimentos, na expansão ou crise das lavouras. A crise de crédito acelerou a internalização de um esquema de financiamento que já era largamente praticado nos Estados Unidos, em que a grande Trading busca recursos no mercado financeiro, via bolsa de futuros, e financia o custeio do produtor agrícola dos produtos que lhe servem de matéria-prima. Como apontou Gonçalves (2005) este processo aprofundou a financeirização da agricultura, após a crise do tradicional Sistema Nacional de Crédito Rural-SNCR. Com este, o produtor se inseriu no sistema financeiro para viabilizar investimentos e modernização. Num segundo momento, os recursos financeiros para custeio tornaram-se expressivos. Neste terceiro momento, com o corte de recursos oficiais, as vendas antecipadas, como forma de obtenção de recursos e a compra de insumos tornaram-se parte de um amplo movimento de circulação de títulos financeiros e dependência com relação às tradings internacionais. Assim, o aprofundamento da financeirização e da internacionalização do agro brasileiro ocorreram conjuntamente.

Com o fortalecimento dos agentes dos complexos agroindustriais, em especial as agroindústrias e as tradings de grãos, com escala de atuação nacional e internacional, diversas questões surgem na compra antecipada de safra. Para o produtor, trata-se de obter recursos para custeio da safra e ao mesmo tempo 


\section{A geografia do mercado mundial de produtos agroalimentares e o papel do Brasil}

garantir a venda antecipada de parte da produção. Para a indústria, trata-se de garantir antecipadamente parte da matéria-prima necessária. Como as grandes tradings de soja são também produtoras de insumos, os produtores agrícolas formam o seu mercado consumidor de sementes, fertilizantes e defensivos.

A partir de 1994, as compras antecipadas ganharam um mecanismo mais sofisticado com a criação da Cédula do Produto Rural (CPR), a qual pode ser comercializada na Bolsa de Mercadorias e Futuros (BM\&F). Além da obtenção de crédito para custeio de safra, a existência da CPR e a possibilidade de venda no mercado de futuros, ampliaram também a proteção contra a queda de preços para o produtor. Isto ocorreu juntamente com o desmonte da Política de Garantia de Preços Mínimos- PGPM. As vendas antecipadas e a captação de recursos via CPR tornaram-se prática comum nas principais regiões produtoras. No entanto, seus recursos se direcionam a custeio de safras e não aos investimentos. Conforme dados de Viana (2004), o número de contratos de CPR passa de 1,4 mil em 1998 para 29,3 mil em 2003. Em valores, no mesmo período, os contratos passam de $\mathrm{R} \$$ 78,8 milhões para $R \$ 1,5$ bilhões.

A venda da CPR na BM\&F possibilitou aos compradores (cooperativas, tradings, agroindústrias) uma fonte adicional de recursos para a compra antecipada além de um ganho especulativo, pois o valor repassado ao produtor sofre um desconto do valor da venda da $\mathrm{CPR}^{7}$. Como a CPR se constitui em um título financeiro, nos períodos de elevação de preços de commodities, foram atraídos inúmeros compradores para esses títulos. Esse movimento acompanhou a tendência internacional de especulação financeira a partir de derivativos. Nos anos de 2006 a 2008, o movimento internacional nas bolsas de mercadorias e futuros foi recorde.

\footnotetext{
${ }^{7}$ Informações levantadas junto ao Grupo Vanguarda do Brasil em Mato Grosso, um dos maiores do Brasil, e no Condomínio Marechal Rondon, associação que congrega 13 grandes produtores de soja de Campo Novo dos Parecis (MT) deixaram claro a importância das vendas antecipadas e da CPR para a continuidade da produção no momento de corte de recursos. No entanto, afirmaram que estes recursos eram destinados para custeio e que os investimentos caíram muito no período, só recuperando-se com a elevação dos recursos oficiais a partir de 2003.
} 
No Brasil, o volume de contratos futuros de soja passa de 7,2 mil em 2004, para 196,2 mil em $2007^{8}$. Em 2003 representavam apenas 0,3\% do total de contratos de commodities agrícolas na BM\&F, chegando em 2007 a $8,8 \%$. Os contratos de milho passam 4,5 mil em 2002 (0,6\% do total) para 208,8 mil em 2007 ( $9,4 \%$ do total). Em termos de valores a evolução também foi expressiva, em especial para a soja, que embora realizando um número menor de contratos, movimenta valores expressivamente mais elevados que o milho.

O Brasil acompanhou o movimento mundial de expansão das bolsas de mercadorias e futuros do período após 2002 e em especial em 2006 e 2007. O recurso às bolsas, em especial via CPR, tornou-se central para o financiamento das lavouras mais dinâmicas e com perspectivas de exportação, sobretudo pelo papel das grandes tradings.

A crise internacional de 2008 abalou a capacidade das tradings de continuarem a financiar as compras antecipadas, uma vez que as matrizes europeias e norte-americanas passaram por sérios problemas. Assim já na safra de 2009 houve escassez de crédito via CPR, levando grande número de produtores a se apoiarem novamente no SNCR. Desde 2005-2006 as renegociações de dívidas e os novos recursos injetados pelo Governo Federal garantiram os financiamentos, tanto para os produtores que estavam ligados as tradings quanto aos demais.

No momento em que os produtores, especialmente do Centro-Oeste, não puderam mais contar com os recursos internacionais, mobilizaram seus representantes para pressionar o governo federal a ampliar os recursos de crédito rural, bem como realizar novas renegociações das dívidas em andamento.

\section{CONSIDERAÇÕES FINAIS}

$\mathrm{Na}$ última década ocorreram importantes mudanças na geografia da produção agrícola mundial: crescimento significativo do mercado mundial de produtos agrícolas com ampliação da participação dos países da América do Sul nas exportações e países asiáticos nas importações; expressivo movimento de investimentos nas bolsas de mercadorias e de futuros agropecuários aprofundando

\footnotetext{
${ }^{8}$ Todas as estatísticas referentes ao Mercado de Futuros agropecuários no Brasil são de relatórios e informes da BM\&F.
} 


\section{A geografia do mercado mundial de produtos agroalimentares e o papel do Brasil}

a financeirização do setor e levando a um ciclo de inflação mundial de alimentos; fusões entre bolsas de mercadorias e de valores ampliando o poder destas e a integração entre os mercados agropecuários; acirramento dos conflitos entre países produtores agrícolas em torno das questões de liberalização comercial e subsídios, em especial na União Europeia e nos EUA.

Com o crescimento dos mercados de futuros agropecuários passou a vigorar uma lógica financeira de antecipação e de expectativas, que subverteu a própria tendência tradicional de os preços serem estabelecidos após as safras. Neste novo momento, os preços são negociados e oscilam fortemente antes mesmo do plantio. O que determina a oscilação de preços não é a materialização das safras, mas o que se "espera delas" pelos analistas de investimentos e pelos investidores. Isto abre todo um novo campo de análises e de disputa por políticas e por espaços. A negociação do preço futuro entre grupos econômicos e produtores tornou-se elemento central de conflito e de estabelecimento dos montantes de capital para custeio e investimentos a que o produtor terá acesso. Embora esta tendência seja mais forte entre produtos voltados aos mercados externos, os produtos de mercado interno também são afetados, pois as negociações locais entre compradores (grupos agroindustriais, empresas de vendas de insumos, cerealistas entre outros), agentes de financiamento e produtores agrícolas vem crescentemente obedecendo a mesma lógica.

O Brasil se inseriu neste panorama de maneira direta. A ampliação das exportações agrícolas brasileiras, ocorrida na última década, se deu no bojo do aprofundamento da internacionalização e da financeirização da agricultura brasileira. As tradings agrícolas aprofundaram sua presença nas regiões produtoras brasileiras atuando como financiadoras-vendedoras de insumos-compradoras da produção. A criação de títulos de mercados futuros, como a Cédula do Produto Rural-CPR, e os cortes de recursos oficias de crédito rural, ocorridos na década de 1990, facilitaram o processo. Isto levou a que os preços internacionais das commodities agrícolas e os mercados externos interessassem, não apenas pela geração de demanda, mas como fonte de recursos financeiros para as lavouras. A BM\&F se tornou uma das maiores bolsas de mercadorias do mundo, com crescimento acelerado dos contratos agropecuários. Este processo vem acelerando a concentração da produção entre 
produtores mais capitalizados e com escala para negociações com os grupos internacionais.

\section{REFERÊNCIAS}

AOUN, S.E.A. Dinâmica das Fusões e Aquisições no Investimento Direto Estrangeiro: Especificidade Da Indústria De Alimentos e Bebidas No Brasil, 19962006. In: Informações Econômicas, São Paulo, v.38, n.3, mar. 2008.

BENETTI, M.D. Globalização e Desnacionalização do Agronegócio Brasileiro no Pós-1990. Documentos FEE, n 61. Porto Alegre: FEE, 2004.

CARVALHO, M.S. Lugares e Paladares: Uma contribuição geográfica à diversidade do consumo alimentar no brasil. RA'E GA- O Espaço Geográfico em Análise, Curitiba, n. 15, p. 95-111, Editora UFPR. 2008.

DELGADO, G.C. Especialização primária como limite ao desenvolvimento. In: Desenvolvimento em Debate, v.1, n.2, p.111-125, janeiro-abril e maio-agosto 2010.

DINIZ FILHO, L.L. Agricultura e mercado no brasil: revendo as visões da geografia sobre os condicionantes da produção agrícola no capitalismo. RA'E GA- O Espaço Geográfico em Análise, 23. Curitiba, Departamento de Geografia - UFPR. 2011.

FAO. Aumento del precio de los alimentos: hechos, perspectivas, impacto y acciones requeridas. Conferencia de alto nivel sobre la seguridad alimentaria mundial: los desafíos del cambio climático y la bioenergia. FAO: Roma, 2008.

The State of food and Agriculture. Food Aid and food Security? Roma: FAO, 2006.

FMI. World Economic Outlook. Housing and the business cycle. April 2008.

GONÇALVES, J.S. Agricultura Sob a Égide do Capital Financeiro: Um Passo Rumo ao Aprofundamento do Desenvolvimento dos Agronegócios. In: Informações Econômicas, São Paulo, V. 35, n. 4, abr, 2005.

GUGLIELMO, R. Um Novo Capítulo da Geografia: a Geografia do Consumo e da Distribuição. In: GEORGE, Pierre et al. A Geografia Ativa. 4ª ed. São Paulo: Difel, 1975. 
HOLANDA FILHO, S.B. A Organização Mundial do Comércio e os Países em Desenvolvimento. In: Cadernos Geográficos, n. 8, Florianópolis, Março, 2005.

LENIN, V.I. Imperialismo: Fase Superior do Capitalismo. São Paulo: Global, 1982.

MEDEIROS, M.C. A Geografia Econômica do Setor Agroalimentar Brasileiro: Investimentos, Recursos Ociosos e Dinâmica Cíclica (1990-2007). FFLCH//USP (Tese de Doutorado em Geografia Humana). 2009.

- A geografia do consumo de alimentos e a dinâmica do setor agroalimentar brasileiro. Cadernos Geográficos (UFSC), v. 23, p. 07-89, 2010.

MONBEIG, P. Capital e Geografia. In: Novos Estudos de Geografia Humana Brasileira. Rio De Janeiro: Difel, 1957.

OMC. International Trade Statistics. Disponível em www.wto.org. 2006.

PRATES, D.M. A alta recente dos preços das commodities. In: Revista de Economia Política, vol. 27, no 3 (107), julho-setembro/2007.

SANTOS, M. Por Uma Geografia Nova. $3^{a}$ ed. São Paulo: Hucitec, 1986.

VIANA, J.A. Cédula do Produto Rural: indicador de modernização do agronegócio? In: Bahia Agrícola, v6, n.2, junho de 2004.

WEDEKIN, I. A globalização e a expansão dos mercados futuros agropecuários. In: Seminário "Perspectivas para o Agribusiness em 2008 e 2009". São Paulo: BM\&F, 24 de Junho de 2008. 